\title{
Assessment of film forming potential of Cordia dichotoma fruit mucilage (Boraginaceae): Alfuzosin hydrochloride as a drug of choice
}

\author{
Lohithasu Duppala $^{1 *}$, Sarada Anepu ${ }^{2}$, Hema Naga Durga Divvela ${ }^{2}$, Rajya Lakshmi Teku ${ }^{2}$ \\ ${ }^{1}$ Division of Pharmaceutics, GITAM Institute of Pharmacy, GITAM University, Visakhapatnam, India. \\ ${ }^{2}$ Division of Pharmaceutical Technology, A.U College of Pharmaceutical Sciences, Andhra University, Visakhapatnam, India.
}

\begin{tabular}{l} 
ARTICLE INFO \\
\hline Article history: \\
Received on: $15 / 12 / 2015$ \\
Revised on: $05 / 02 / 2016$ \\
Accepted on: $27 / 02 / 2016$ \\
Available online: $28 / 05 / 2016$ \\
\hline Key words: \\
Alfuzosin hydrochloride, \\
Cordia dichotoma fruit \\
mucilage and Transdermal \\
films.
\end{tabular}

\begin{abstract}
The objective of this present study was to develop and evaluate transdermal films of alfuzosin hydrochloride for controlled release at a predetermined rate over a prolonged period of time and assessment of film forming ability Cordia dichotoma fruit mucilage using alfuzosin as drug of choice. The films of alfuzosin were prepared by solvent evaporation technique. The formulations, from F1 to F3 contain Cordia dichotoma fruit mucilage (CDFM; $8 \%, 12 \%$ and 16\%) and the formulations, from F4 to F6 contain CDFM along with sodium alginate $(125 \mathrm{mg}, 150 \mathrm{mg}$ and $175 \mathrm{mg}$ ). Glycerin and propylene glycol were used as plasticizer; span-80 used as permeation enhancer; methyl paraben and propyl paraben were used as preservatives (in case of plant mucilage as polymer) in all the formulations. Fourier transform infra red spectral analysis studies showed that there is no drug polymer incompatibility. The films of alfuzosin were prepared by using different polymers such as $C$. dichotoma and also in combination with sodium alginate that had shown good results for all the evaluated parameters within the range. In vitro drug release studies had shown that the maximum release of drug was observed for F3 formulation was $91.87 \pm 1.34$ at 24 hrs and F6 formulation was $99.62 \pm 0.14$ at 24 hrs. The concentration of CDFM is increased from $8 \%$ to $16 \%$ that leads to enhancement of dissolution rate. In-vitro drug release studies of optimized formulations, F3 formulation followed first order and F6 formulation followed zero order kinetics. The obtained results were concluded that CDFM have good film forming ability alone and combination with sodium alginate.
\end{abstract}

\section{INTRODUCTION}

The transdermal drug delivery systems (TDDS) are topically administered medicaments in the form of films that deliver the active ingredient for systemic effects after across through the skin barriers at a predetermined, controlled rate to avoid first pass effect and improve the patient compliance (Chandrashekar et al., 2008). A transdermal patch, which may be either an active or a passive design, is a device which provides an alternative route for administering drugs the patients who cannot tolerate oral dosage forms such as vomiting patients, provides suitability of self medication to deliver the drug for extended period of time for improvement of bioavailability and it provides non-invasiveness. The drug enters into the blood stream directly across the skin barriers through diffusion process. Since there is

\footnotetext{
* Corresponding Author

Lohithasu Duppala, Division of Pharmaceutics, GITAM Institute of Pharmacy, GITAM University, Visakhapatnam, India.

Email:lohithasu@gmail.com
}

high concentration on the patch and low concentration in the blood, the drug will keep diffusing into the blood for a extended period of time to maintain the uniform plasma levels and enhance the therapeutic efficacy by reducing fluctuations (Chien Yie et al., 1987; Kumboji et al., 2013; Chetan et al., 2015). Cordia dichotoma, plant belonging to family Boraginaceae is medium sized tree and fruits are globose, yellowish-brown, pink or black and pulpy. The plant grows not only in India and but also in other warmer regions. The plant fruits are used as cooling, astringent, anti-ulcer (Kuppast et al., 2008), emollient, expectorant, anthelmintic, purgative and diuretic. The medicinal or pharmacological properties of $C$. dichotoma such as analgesic, anti-inflammatory (Rapisarda et al., 1992) and hepatoprotective have been reported. The mucilage is initially white in color but changes to brownish black on exposure to atmosphere and sparingly soluble in water but swells in contact with water, giving a highly viscous solution. It is a polyuronide consisting of arabinose, galactose, and glucoronic acid in the proportion of 10:7:2 moles; rhamnose is present in traces (Wassel et al., 1987; Rapisarda et al., 1992; Rajesh et al., 2000; Patil et al., 2010; Pattnaik et al., 2009; Prasad et al., 2013). 
The various pharmaceutical applications of Cordia dichotoma, C. myxa mucilage such as tablet binder (Vidyasagar et al., 2010), emulsifier, mucoadhesive property, gastro retentive delivery (Sonia et al., 2015), matrix forming agent (Ahad et al.,2009; Lohithasu et al., 2015), patches (Harshal et al., 2014), herbal excipient (Harshal et al., 2015), pharmaceutical adjuvant (Somya et al., 2015), nanoparticles and micro particulate drug delivery systems (Priyanka et al., 2014). Alfuzosin hydrochloride, a quinazoline derivative, is a selective and competitive alpha(1)adrenergic blocker in lower urinary tract that relaxes the smooth muscles in the prostate and bladder neck, making it improvement of urination and reduction in symptoms in benign prostate hyperplasia (BPH-enlarged prostate) due to inhibition of these adrenoreceptors. The absolute bioavailability of alfuzosin is about $49 \%$ under fed conditions. $\mathrm{T}_{\max }$ is $8 \mathrm{~h}$ and the $\mathrm{C}_{\max }$ and AUC are about $13.6 \mathrm{ng} / \mathrm{ml}$ and $194 \mathrm{ngh} / \mathrm{ml}$, respectively. Transdermal route is more convenient, easy and an alternative choice of route of administration for such drugs. The physicochemical parameters such as molecular mass, $\log \mathrm{P}$ value, melting point and solubility of alfuzosin are $389.49 \mathrm{~g} / \mathrm{mol}, 1.51$ at a $\mathrm{pH}$ of $7.4,230{ }^{\circ} \mathrm{C}$ and > $10 \%$ respectively. These encouraging parameters make it an ultimate suitable drug candidate for transdermal delivery systems (TDDS) (Kumboji et al., 2013; Pattanaik et al., 2009; Radha et al., 2013; Santoshnaidu et al., 2014; Satyanarayan et al., 2011; Rajpur et al.,2015).

\section{MATERIALS AND METHODS}

Alfuzosin hydrochloride was obtained as a gift sample from Cipla Ltd. (Mumbai, India). Sodium alginate and span-80 were procured from Loba Chemie Pvt Ltd. (Mumbai, India). Glycerin from SD fine Chemicals, used as plasticizer, propylene glycol, methyl paraben, propyl paraben were purchased from BDH, England.

\section{Drug- polymer interaction studies}

\section{Fourier Transform Infra-Red (FT-IR) spectral analysis}

FTIR spectral analysis was found to be reliable technique for predicting the possible interactions between alfuzosin and other ingredients. FTIR spectra of pure alfuzosin hydrochloride and mixture of drug and polymers were mixed with IR grade $\mathrm{KBr}$ in the ratio of 100:1 and corresponding pellets were prepared by applying pressure in a hydraulic press. The pellets were scanned over a wave number range of $4000-400 \mathrm{~cm}^{-1}$ in Fourier transform infrared spectrophotometer (Bruker, model 10048657 Alpha-T, AT-001 opus software).

\section{Extraction of $\boldsymbol{C}$. dichotoma fruit mucilage}

The collected plant and fruits had been identified and authenticated by Dr. N.S.N. Swamy, Department of Botany, Palakonda, Srikakulam district, Andhra Pradesh and, India with the reference voucher specimen number of Cordia/No.DOB/ Pharm.Tech/0077/2015-16. The fruits of Cordia dichotoma were collected from surrounding area of Srikakulam, Andhra Pradesh, India. Fresh Cordia dichotoma fruits were collected and the seeds were removed prior to extraction process. The fruits were sliced, crushed, homogenized with 5-10 times its weight of distilled water and the clear, viscous solution decanted. The fruit mucilage was precipitated with 3- 4 volumes of ethanol and washed with more ethanol followed by acetone. The fruit mucilage so obtained was dried under vacuum. The precipitate was washed 2-3 times with 95\% ethanol. After complete washing, filtered through muslin cloth, dried, powdered, passed through a sieve no. 80 and stored in a desiccator for further use (Lohithasu et al., 2015). The mucilage was white colour, characteristic odour and amorphous in nature.

\section{Preparation of transdermal films}

\section{The transdermal films of alfuzosin hydrochloride were prepared by solvent evaporation technique.}

The mould of $5 \mathrm{~cm}$ length and $5 \mathrm{~cm}$ width with a total area of $25 \mathrm{~cm}^{2}$ as made-up was used for the preparation of transdermal films. The mould bottom was wrapped with aluminium foil. The various concentrations of mucilage $(8 \%, 12 \%$ and $16 \%$ ) were taken in a beaker. Then add propylene glycol, glycerin, span-80, propyl paraben, methyl paraben and alfuzosin hydrochloride $(5 \mathrm{mg}$ ) was added with constant stirring using magnetic stirrer for $2 \mathrm{~h}$ at $800 \mathrm{rpm}$. The obtained uniform solution was casted on the aluminium foil and dried at $40{ }^{\circ} \mathrm{C}$ in the hot air oven for $24 \mathrm{~h}$. For prevention of fast evaporation of solvent, to place an inverted funnel over the mould. After $24 \mathrm{~h}$ the dried films were taken out from hot air oven and stored in a desiccator for further evaluation studies. Compositions of different formulations are shown in Table 1.

Table 1: Composition of various formulation batches of alfuzosin transdermal films.

\begin{tabular}{|c|c|c|c|c|c|c|}
\hline \multirow[t]{2}{*}{ Ingredients } & \multicolumn{6}{|c|}{ Formulation codes } \\
\hline & F1 & F2 & F3 & F4 & F5 & F6 \\
\hline Alfuzosin hydrochloride (mg) & 5 & 5 & 5 & 5 & 5 & 5 \\
\hline$* \operatorname{CDFM}(\%)$ & 8 & 12 & 16 & 8 & 12 & 16 \\
\hline Sodium alginate (mg) & - & - & - & 125 & 150 & 175 \\
\hline Glycerin (ml) & 1 & 1 & 1 & 1 & 1 & 1 \\
\hline Propylene glycol (ml) & 0.2 & 0.2 & 0.2 & 0.2 & 0.2 & 0.2 \\
\hline Span- $80(\mathrm{ml})$ & 0.09 & 0.09 & 0.09 & 0.09 & 0.09 & 0.09 \\
\hline Methyl paraben (mg) & 25 & 25 & 25 & 25 & 25 & 25 \\
\hline Propyl paraben (mg) & 15 & 15 & 15 & 15 & 15 & 15 \\
\hline Water up to & 20 & 20 & 20 & 20 & 20 & 20 \\
\hline
\end{tabular}

*CDFM = Cordia dichotoma fruit mucilage 


\section{Evaluation of transdermal patch Thickness of the film}

The thickness of the formulated film was measured at least 3 different points using a digital caliper and average thickness of three readings for each formulation was calculated.

\section{Weight uniformity}

The films of different batches were dried at $60{ }^{\circ} \mathrm{C}$ for 4 hrs before testing. Three films from each batch were accurately individually in a digital balance and the average weight was calculated.

\section{Folding endurance}

This was determined manually by repeatedly folding the strip film at the same place until it broke. The number of times the film could be folded at the same place without breaking/cracking gave the value of folding endurance.

\section{Percentage moisture absorption}

The films were weighed accurately and placed in the desiccators containing $100 \mathrm{ml}$ of saturated solution of potassium chloride or ammonium chloride, which maintains $80-90 \%$ relative humidity. After 3 days, the films were taken out and weighed. The percentage moisture absorption was calculated using the following formula:

$\%$ Moisture absorption $=\frac{\text { Final weight }- \text { Initial weight }}{\text { Initial weight }} \times 100$

\section{Percentage moisture loss}

The films were weighed accurately and kept in a desiccators containing anhydrous calcium chloride at $40{ }^{\circ} \mathrm{C}$ for 24 hours. After 3 days, the films were taken out and re-weighed until there was no further change in the weight of individual film. The percentage moisture content was calculated using the formula:

$\%$ Moisture loss $=\frac{\text { Final weight }- \text { Initial weight }}{\text { Initial weight }} \times 100$

\section{Moisture content}

The prepared films were weighed individually and kept in desiccator containing activated silica at room temperature for 24 hrs. The films were weighed again, until constant weight is achieved. The $\%$ moisture content was calculated as a difference between initial and final weight with respect to final weight.

$\%$ Moisture content $(\mathrm{MC})=\frac{\text { Initial weight }- \text { Final weight }}{\text { Initial weight }} \times 100$

\section{Water vapour transmission rate}

Glass vials of $5 \mathrm{ml}$ capacity were washed thoroughly and dried to a constant weight in an oven. About $3 \mathrm{~g}$ of fused calcium chloride was taken in the vials and the polymer films of $2.25 \mathrm{~cm}^{2}$ were fixed over the brim with the help of an adhesive tape. Then the vials were weighed and stored in a humidity chamber of 80$90 \% \mathrm{RH}$ condition for a period of $24 \mathrm{~h}$. The vials were removed and weighed at $24 \mathrm{hrs}$ time intervals to note down the weight again.

Water vapour transmission rate

$$
=\frac{\text { Final weight }- \text { Initial weight }}{\text { Time } \times \text { Area }} \times 100
$$

\section{Tensile strength}

Mechanical properties of the prepared films were evaluated by using a microprocessor based advanced force gauze (Ultra Test, Mecmesin, UK) equipped with a $25 \mathrm{~kg}$ load cell. The prepared film strip with dimensions of $60 \times 10 \mathrm{~mm}$ and free from air bubbles or physical imperfections were held between two clamps positioned at a distance of $3 \mathrm{~cm}$. During measurement of film strip, the top clamp at a rate of $2 \mathrm{~mm} / \mathrm{s}$ pulled the strips to a distance till the film broke. The force and elongation were measured $(n=3)$ when the film broke. The mechanical properties were calculated according to the following formulae.

$$
\begin{aligned}
& \text { Tensile strength } \\
& =\frac{\text { Force at break }(\mathrm{kg})}{\text { Initial cross sectional area of the sample }\left(\mathrm{mm}^{2}\right)} \\
& \text { Elongation at break }\left(\% \mathrm{~mm}^{-2}\right) \\
& =\frac{\text { Increase in length }(\mathrm{mm}) \times 100}{\text { Original length }(\mathrm{mm}) \times \text { Cross sectional area }} \\
& \text { Elastic modulus }=\frac{\text { Force at corresponding strain }(\mathrm{kg})}{\text { Cross sectional area }\left(\mathrm{mm}^{2}\right)} \\
& \qquad \frac{1}{\text { Corresponding strain }} \\
& \text { Strain }=\frac{\text { Tenstile strength }}{\text { Elastic modulus }}
\end{aligned}
$$

The measurement of tensile strain gives an indication of the strength and elasticity of the patch, reflected by the characteristic parameters, tensile strength (TS), elastic modulus (EM) and elongation at break (E/B). A soft and weak polymer is characterized by a low TS, EM and E/B; a hard and brittle polymer is characterized by a moderate TS, high EM and low E/B; a soft and tough polymer is characterized by a moderate TS, low EM and high $\mathrm{E} / \mathrm{B}$; where as a hard and tough polymer is characterized by a high TS, EM and E/B. Another the characteristic parameter strain has been used as an indicator of the overall mechanical quality of the patch.

A high strain value indicates that the patch is strong and elastic. Hence, it is concluded that a suitable transdermal patch should have a relatively high TS, E/B and strain but low EM (Kumboji et al., 2013).

\section{Drug content uniformity of films}

The drug content in each batch of formulated transdermal films was determined by cut into pieces and dissolving each film in $100 \mathrm{ml}$ solution (50 ml of methanol and $50 \mathrm{ml}$ of water) and 
then filtering with Whatman filter paper $(0.45 \mu \mathrm{m})$. The drug content was analyzed by suitable dilution as per the reported method by using UV-spectrophotometer at $242 \mathrm{~nm}$.

\section{Scanning electron microscopy}

Film morphology of optimized formulations F3 and F6 were characterized before permeation and after permeation study after 24 hrs by using scanning electron microscopy.

\section{Drug release kinetic study}

The drug in vitro release studies from alfuzosin $\mathrm{HCl}$ transdermal films were performed using Franz diffusion cell (modified Keshary-Chien diffusion cell) with cellophane membrane. The cell consists of two compartments, the donor and the receptor compartment.

The donor compartment was in contact with ambient conditions of the atmosphere. The receptor compartment was in contact with a solution in the receptor compartment (phosphate buffer $\mathrm{pH}$ 7.4) and the contents were stirred with magnetic bead driven by magnetic stirrer. One film of $1 \mathrm{~cm}^{2}$ was placed in the donor compartment of the diffusion cell. The receptor fluid $(5 \mathrm{ml})$ was withdrawn at predetermined time intervals and replaced immediately with same volume of phosphate buffer $\mathrm{pH} 7.4$ to maintain sink conditions.

The samples were analyzed for drug content at $242 \mathrm{~nm}$ using UV-visible spectrophotometer (Shimadzu, Japan) after suitable dilution with phosphate buffer $\mathrm{pH} 7.4$ against phosphate buffer of $\mathrm{pH} 7.4$ as reference. To examine the drug release kinetics and mechanism, the drug release data of optimized batch F3 and F6 were fitted to various kinetic models.

\section{Stability studies}

Stability studies were carried out on optimized formulations F3 and F6 as per ICH guidelines for two months and various parameters were studied during stability study. The short term stability studies were carried out on prepared films at different temperature and humidity according to $\mathrm{ICH}$ guidelines: $\left(25 \pm 2{ }^{\circ} \mathrm{C} / 60 \% \mathrm{RH}\right)$ and $\left(45 \pm 2{ }^{\circ} \mathrm{C} / 75 \% \mathrm{RH}\right)$ a period of 60 days. The films were wrapped in aluminum foil and stored in desiccator for stability study. The films were characterized for drug content and other parameters at regular intervals.

\section{RESULTS AND DISCUSSION}

\section{Pre-formulation studies on alfuzosin hydrochloride}

The solubility of alfuzosin hydrochloride was determined in water. The solubility studies indicate that the drug is freely soluble in water.

\section{Drug-Excipients Compatibility Studies \\ Fourier transform infrared (FTIR) analysis}

FTIR spectra of drug, physical mixture of drug with different polymers, were recorded and examined. FTIR spectra of alfuzosin hydrochloride showed all the principal peaks with reference to their functional groups. The observed FTIR spectrum of drug was matched with reference spectra. The results showed there was no appearance or disappearance of peaks in the excipients-drug mixture this confirmed the absence of any chemical interaction between the drug and the polymers. The FTIR spectra of pure drug, physical mixture of drug with CDFM, physical mixture of drug, CDFM with sodium alginate and physical mixture of drug with sodium alginate are shown in Fig. 1, Fig. 2, Fig.3 and Fig.4. respectively.

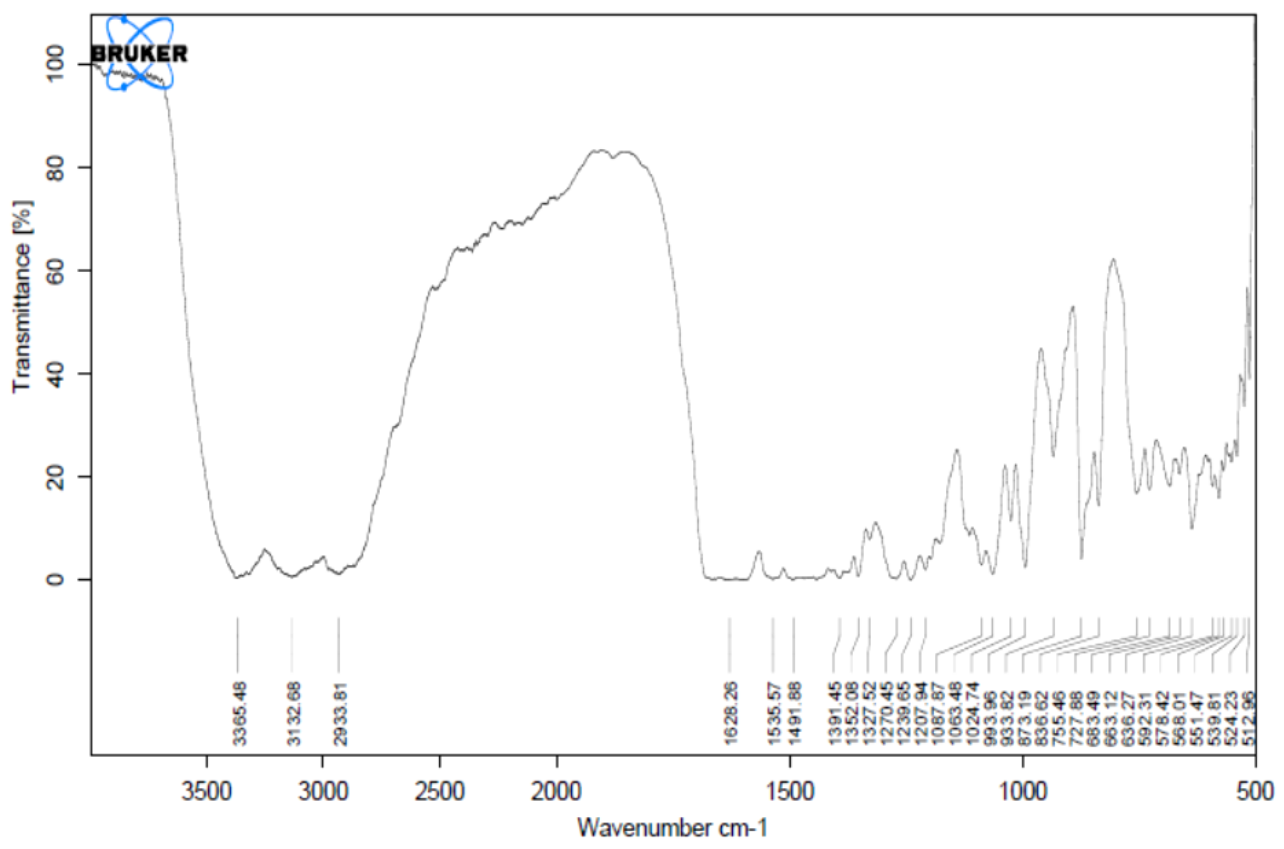

Fig. 1: FTIR spectrum of alfuzosin hydrochloride 


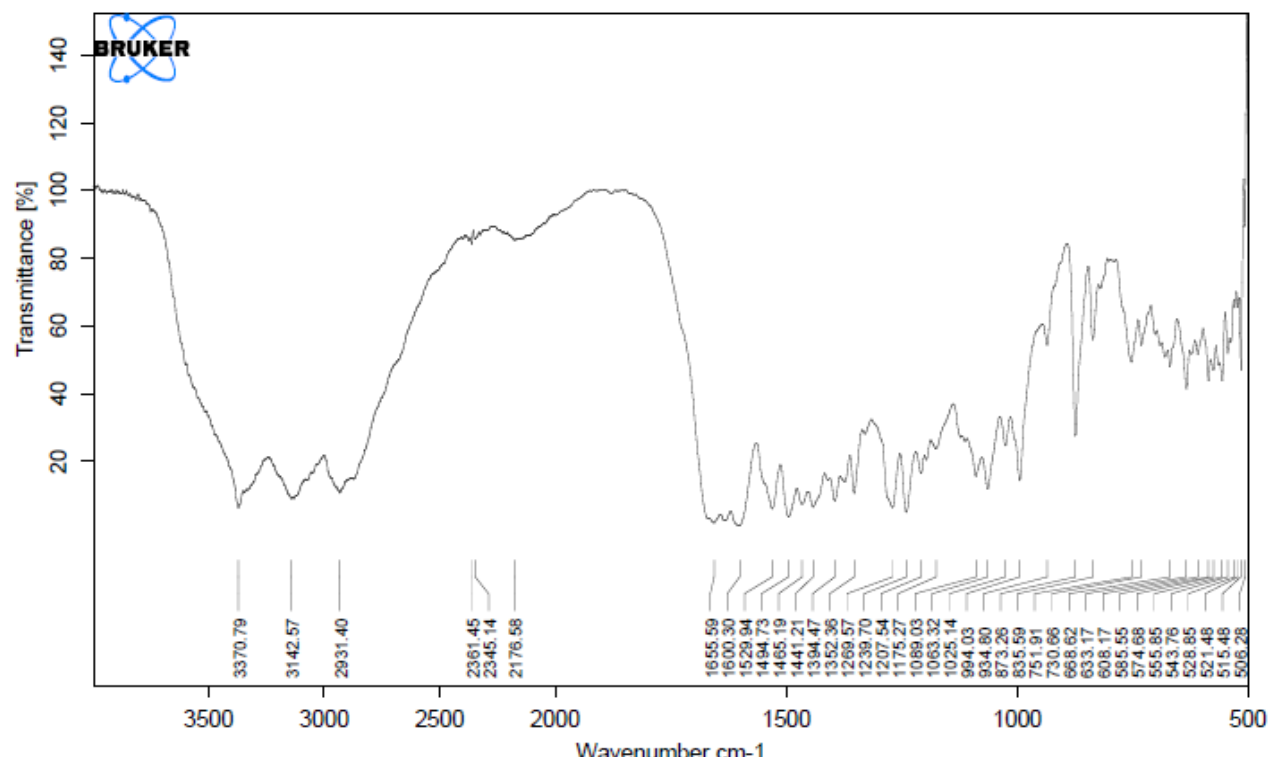

Fig. 2: FTIR spectrum of physical mixture of alfuzosin hydrochloride and CDFM.

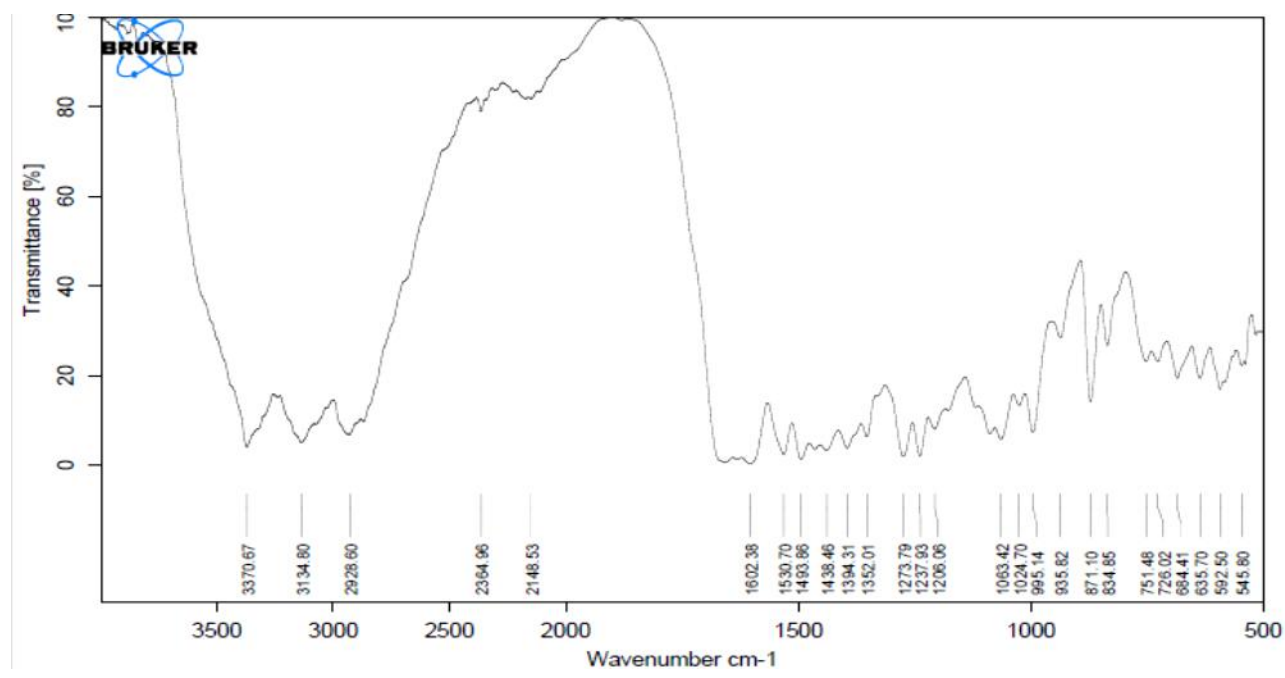

Fig. 3: FTIR spectrum of physical mixture of alfuzosin hydrochloride, CDFM and sodium alginate.

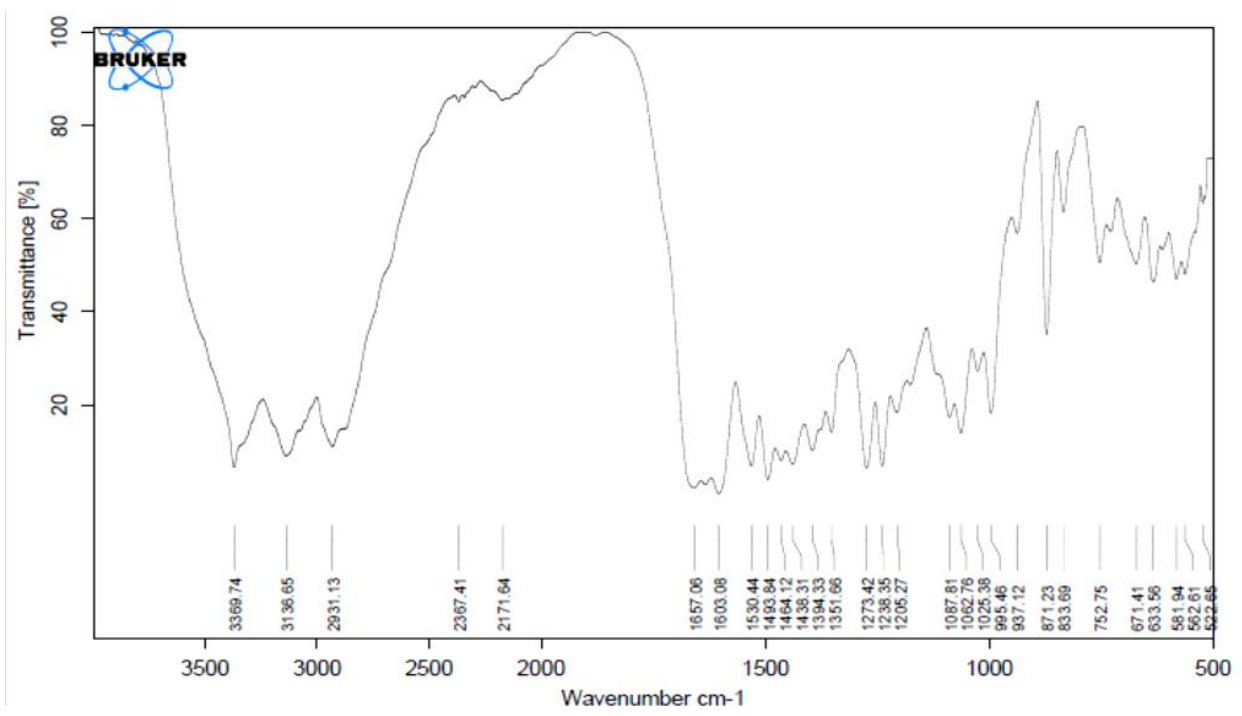

Fig. 4: FTIR spectrum of physical mixture of alfuzosin hydrochloride and sodium alginate. 
Table 2: Evaluation parameters and its results of alfuzosin $\mathrm{HCl}$ films.

\begin{tabular}{|c|c|c|c|c|c|c|c|c|c|c|}
\hline Formulation & $\begin{array}{l}\text { Thickness } \\
\text { (mm)* }\end{array}$ & $\begin{array}{c}\text { TS } \\
\left(\mathbf{N} / \mathbf{m m}^{2}\right)^{*}\end{array}$ & $\begin{array}{c}\text { Elongation } \\
(\%)^{*}\end{array}$ & $* \mathbf{F E}$ & $\begin{array}{l}\text { Weight } \\
\text { (mg) }\end{array}$ & $\begin{array}{c}\% \mathrm{MC} \\
(\% \mathrm{w} / \mathrm{w})\end{array}$ & ML(\%) & $\begin{array}{l}\text { MA } \\
(\%)\end{array}$ & $\begin{array}{l}\text { DC } \\
(\%)\end{array}$ & $\begin{array}{c}\text { MVT } \\
\left(\mathrm{gcm}^{-2} \mathbf{h}^{-1}\right) 10^{-4}\end{array}$ \\
\hline F1 & $0.85 \pm 0.03$ & $0.242 \pm 0.14$ & $10.00 \pm 0.11$ & $101 \pm 1.1$ & $400 \pm 0.015$ & $3.65 \pm 0.03$ & $3.92 \pm 1.04$ & $6.00 \pm 2.12$ & $97.4 \pm 0.34$ & $0.92 \pm 0.52$ \\
\hline F2 & $0.88 \pm 0.04$ & $0.256 \pm 0.27$ & $14.56 \pm 0.21$ & $112 \pm 1.4$ & $403 \pm 0.011$ & $3.78 \pm 0.04$ & $4.23 \pm 0.52$ & $6.25 \pm 0.18$ & $97.7 \pm 0.56$ & $1.28 \pm 0.22$ \\
\hline F3 & $0.90 \pm 0.03$ & $0.261 \pm 0.05$ & $18.43 \pm 0.37$ & $116 \pm 1.2$ & $406 \pm 0.015$ & $3.79 \pm 0.07$ & $4.78 \pm 0.24$ & $8.24 \pm 0.75$ & $99.7 \pm 0.34$ & $1.81 \pm 0.30$ \\
\hline F4 & $0.94 \pm 0.02$ & $0.275 \pm 0.18$ & $23.23 \pm 0.37$ & $125 \pm 1.7$ & $408 \pm 0.012$ & $3.89 \pm 0.01$ & $6.10 \pm 0.53$ & $9.11 \pm 1.27$ & $98.6 \pm 0.39$ & $2.65 \pm 0.51$ \\
\hline F5 & $0.96 \pm 0.05$ & $0.276 \pm 0.12$ & $24.23 \pm 0.39$ & $129 \pm 1.8$ & $409 \pm 0.015$ & $3.79 \pm 0.03$ & $6.13 \pm 0.63$ & $9.13 \pm 1.37$ & $98.4 \pm 0.49$ & $2.69 \pm 0.81$ \\
\hline F6 & $1.04 \pm 0.02$ & $0.279 \pm 0.18$ & $25.62 \pm 0.21$ & $137 \pm 1.1$ & $412 \pm 0.030$ & $3.23 \pm 0.13$ & $6.27 \pm 1.50$ & $9.27 \pm 1.21$ & $99.5 \pm 0.59$ & $3.17 \pm 0.47$ \\
\hline
\end{tabular}

*n=3; standard deviation for three determinations; $\mathbf{T S}=$ Tensile strength $\mathbf{F E}=$ Folding endurance; $\mathbf{M C}=$ Moisture content; $\mathbf{D C}=$ Drug content; $\mathbf{M L}=\mathbf{M o i s t u r e}$ loss; MA= Moisture absorption; MVT= Moisture vapour transmission.

\section{Evaluation of alfuzosin hydrochloride transdermal films}

All the formulated transdermal films (from F1 to F6) were most elegant, flexible, smooth. The thicknesses of formulated transdermal films were ranged from $0.85 \pm 0.03$ to $1.04 \pm 0.02 \mathrm{~mm}$ among the various batches; the uniformity in thickness indicates that the polymeric solution of the drug is well dispersed in the films. The weights ranged between $400 \pm 0.015 \mathrm{mg}$ to $412 \pm 0.030$ $\mathrm{mg}$, the probable reason for slight weight variation may due to viscosity variation of polymeric solution used in the polymeric films.

The $\%$ moisture loss was found to be between $3.92 \pm 1.04$ to $6.27 \pm 1.50, \%$ moisture absorption was found to be $6.00 \pm 2.12$ to $9.27 \pm 1.21$ and $\%$ moisture content was found to be between. $3.65 \pm 0.03$ to $3.23 \pm 0.13$. The result shown that as the concentration of CDFM was increased there was increase in the moisture absorption and loss. The moisture content and moisture uptake of the prepared transdermal film was low, which could help the formulations remain stable and from being a completely dried, reduce brittleness during storage; it could protect the formulations from microbial contamination and reduce bulkiness of films.

The tensile strength of film indicates the strength of film, elasticity of the film and the risk of film cracking. But, no sign of cracking in prepared transdermal films and it was observed that all the batches of transdermal films were strong and flexible. Tensile strength of formulated films was ranges from $0.242 \pm 0.14$ to $0.279 \pm 0.18 \mathrm{~N} / \mathrm{mm}^{2}$. The elongation of formulated matrix transdermal films was ranged from $10.00 \pm 0.11$ to $25.62 \pm 0.21$. The folding endurance represents the ability of film to withstand rupture. It was observed that as the concentration of CDFM was increased there is increase in tensile strength. The folding endurance was measured manually and results indicated that the films would not break and would maintain their integrity with general skin folding when used. It was found to be high in films containing higher amount of the CDFM and it was ranged from $101 \pm 1.1$ to $137 \pm 1.1$. The drug content in formulated films was ranged from $97.4 \pm 0.34$ to $99.5 \pm 0.59 \%$ it indicated that all the batches exhibited fairly uniform drug content.

In vapour transmission, all the formulations were permeable to water vapor. The formulation batches F1 and F2 were indicate less vapour transmission as compared to other transdermal films on day one. The highest vapour permeation 3.17 \pm 0.47 was found with patch F6 on day one. While less permeation $0.92 \pm 0.52$ was found on day one with patch F1, containing lower concentration of CDFM. The enhancement of water vapour transmission increases as concentration of mucilage increases due to effect of plasticizers. The results of evaluation parameters of alfuzosin hydrochloride films are shown in Table 2.

As per stability consideration, accelerated stability studies $\left(40^{\circ} \mathrm{C} / 75 \% \mathrm{RH}, 6\right.$ months duration) on mucilage powder showed that there is no significant difference in the parameters observed during stability study. The mucilage is initially white in color but changes to brownish black on exposure to sunlight exposure and may be prone to oxidation. It is prevented by use of antioxidants ( $0.1 \%$ ascorbic acid and $0.1 \%$ sodium bisulfate) along with mucilage and less moisture content. The extracted CDFM were evaluated for microbial load, CDFM showed 25 colonyforming units per gram (CFU/g) for bacteria and 52 colonyforming units per gram (CFU/g) for fungi (specified limit as per I.P. is not more than $100 \mathrm{CFU} / \mathrm{g}$ ) which shows mucilage were under microbial limit, it also proved that CDFM does not support microbial growth and is free from all the pathogen organisms.

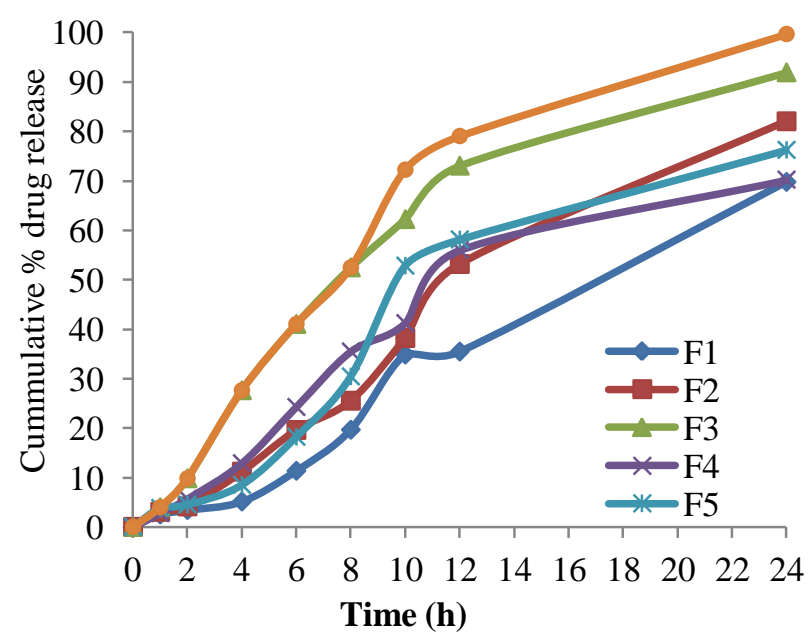

Fig. 5: In vitro drug release from various formulations (F1 to F6)

Table 3: In vitro drug release kinetics of optimized formulations and $\mathrm{R}^{2}$ values

\begin{tabular}{ccccc}
\hline & Zero order & First order & Higuchi model & Korsmeyer- Peppas \\
\hline F3 & 0.995 & 0.997 & 0.945 & 0.874 \\
F6 & 0.945 & 0.926 & 0.911 & 0.901 \\
\hline
\end{tabular}

The in vitro release profile results indicated that the release of drug from films increases with increasing concentration of CDFM. The cumulative percent of drug release in $24 \mathrm{~h}$ was found to be the highest $(99.62 \pm 0.143)$ from formulation F6 
carrying CDFM at high concentration (16\%) and minimum (69.71 \pm 0.168 ) from formulation F1 carrying low proportion of CDFM $(8 \%)$. The drug release was found to increase on increasing the concentration of CDFM in the polymer matrix. Formulation F6 containing CDFM showed cumulative \% drug release of 99.62 \pm 0.143 in $24 \mathrm{~h}$, emerging as a best formulation. The results shown that as the concentration of CDFM was increased and there was increase in dissolution rate.
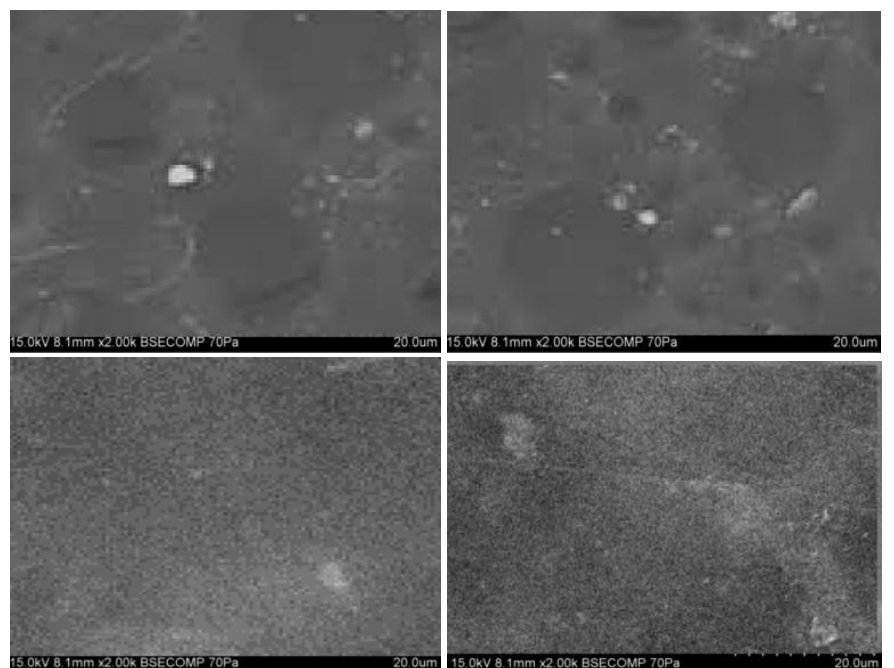

Fig. 6: SEM photograph of (a) F3 film : before permeation study; (b) F6 film: before permeation study; (c) F3 film: after permeation study after 24 h; (d) F6 film: after permeation study after $24 \mathrm{~h}$

The surface topography of the optimized formulations F3 and F6 were studied by scanning electron microscopy. SEM photographs of alfuzosin hydrochloride loaded transdermal patch before permeation and after permeation study, respectively shown in Fig. 6. The SEM photographs shows comparison between the permeation studies of optimized films of alfuzosin. After 24 hours, the films of optimized formulations were collected and subjected to surface topography.

Table 4: Stability study of optimized formulations ( F3 and F6)

\begin{tabular}{ccc}
\hline $\begin{array}{c}\text { Formulation } \\
\text { code }\end{array}$ & $\begin{array}{c}\text { \% Drug content } \\
\text { (After 60 days) }\end{array}$ & $\begin{array}{c}\text { \% Drug release } \\
\text { (After 60 days, at 24 h) }\end{array}$ \\
\hline F3 & 96.8 & 94.23 \\
F6 & 97.9 & 99.06 \\
\hline
\end{tabular}

To know the mechanism of drug release, the release data from the optimized batch were fitted to various kinetic models. The in vitro drug release of alfuzosin hydrochloride from transdermal films is shown in Fig. 5. The stability studies were carried out on the optimized formulations F3, F6 at $30 \pm 2{ }^{\circ} \mathrm{C} / 65$ $5 \% \mathrm{RH}$ and $40 \pm 2{ }^{\circ} \mathrm{C} / 75 \pm 5 \% \mathrm{RH}$ for 60 days as per $\mathrm{ICH}$ guidelines. There was no considerable difference in the physicochemical parameters, in vitro drug release profiles were found to be super impossible with the initial readings at zero day results. It indicates that the formulated films were withstanding with all standard requirement for their stability. The results of stability studies of optimized films were shown in Table.4. The earlier researchers (Patil et al., 2010), studied that drug release from neomycin transdermal films were prepared using $10 \%$ natural polymer (fruit gum) of Cordia dichotoma with different percentage of plasticizer (glycerin $0.05,0.10,0.15,0.20$ and 0.25 $\% \mathrm{w} / \mathrm{v}$ ), same percentage of preservative (methyl paraben $0.2 \%$ $\mathrm{w} / \mathrm{v}$ ) and drug (neomycin $0.2 \% \mathrm{w} / \mathrm{v}$ ). When compared with earlier researchers, the transdermal drug delivery system using $16 \%$ CDFM (F3) shows good film forming potential alone and in combination with sodium alginate.

\section{CONCLUSION}

Six formulations (from $\mathrm{F} 1$ to F6) of different composition were prepared with Cordia dichotoma fruit mucilage alone $(8 \%, 12 \%$ and $16 \%)$ or combination with sodium alginate. When the film forming ability of Cordia dichotoma fruit mucilage is increased due to enhancement of concentration of mucilage from $8 \%$ to $16 \%$ and also combination with sodium alginate. The prepared transdermal films of alfuzosin $\mathrm{HCl}$ using different polymers such as $C$. dichotoma and in combination with sodium alginate had shown good promising results for all the evaluated parameters. From the composition of Cordia dichotoma fruit mucilage alone (formulations F1 to F3; 8\%, 12\% and 16\%) and the composition Cordia dichotoma fruit mucilage (8\%, $12 \%$ and $16 \%$ ) along with sodium alginate (formulations F4 to F6; $125 \mathrm{mg}, 150$ $\mathrm{mg}$ and $175 \mathrm{mg}$ ) is increased leads enhancement of dissolution rate. When sodium alginate used in combination with mucilage for improvement of tensile strength, may be potentiate the film formation. The prepared formulations (from F1 to F6) were subjected to different evaluation parameters. Based on drug release kinetics data, optimization of formulations was done. Evaluation parameters were correlated then based on the in-vitro drug release the matrix optimized formulation F3 shows $91.87 \pm 1.34$, followed first order and formulation F6 was $99.62 \pm 0.14$ followed zero order. It was also concluded that, in future Cordia dichotoma fruit mucilage can also be used as a film forming material.

\section{ACKNOWLEDGEMENTS}

The authors are thankful to GITAM University and Shri Vishnu College of Pharmacy for providing FTIR facilities to carry out this project and also One of the authors, Lohithasu, is thankful to Dr. N. S. N. Swamy, D. Midhun Kumar for providing valuable information to carry out the research work.

\section{REFERENCES}

Ahad HA, Kumar BP, Haranath C and Reddy KS. Fabrication and evaluation of glimepiride Cordia dichotoma G. Forst fruit mucilage sustained release matrix tablets. Int J Chem Sci 2009; 7 (4): 2555-2560.

Chandrashekar NS and ShobhaRani RH. Physicochemical and Pharmacokinetic Parameters in Drug Selection and Loading for Transdermal Drug Delivery. Indian J Pharm Sci 2008 ; 70(1): 94-96.

Chetan $G$ and Rameshwar V. A review on transdermal drug delivery system. The Pharma Innovation Journal 2015; 4(1): 37-43.

Chien Yie W. 1987. Transdermal therapeutic systems, controlled drug delivery: fundamentals \& Applications. Robinson Joseph R, Lee Vincent HL. Eds, New York: Marcel Dekker. pp. 523. 
Harshal PA, Jadhav SM, Jadhav PT and Rachel G. Development and evaluation of mucoadhesive patch using a natural polysaccharide isolated from Cordia dichotoma fruit. J Mol Pharm Org Process Res 2014; 2: 1-6.

Harshal AP and Pravin J. Isolation, characterization and investigation of Cordia dichotoma fruit polysaccharide as a herbal excipient. International Journal of Biological Macromolecules 2015; 72: 228-1236.

Kumboji S, Uma maheshwara rao V, Mahalaskhmi $\mathrm{K}$ and Shalinikrishna B. Selection of optimized transdermal patch of alfuzosin hydrochloride through different approaches. Int J Inv Pharm Sci 2013; 1(6): 515-525.

Kuppast I, Vasudevanyak P, Chandra KP and Satsh KK. Antiulcer effect of Cordia dichotoma Forst fruits against gastric ulcers in rats. Int J Pharmacology 2008; 7(1): 1-5.

Lohithasu D, Madhulatha AVS, Midhunkumar D and Girish P. Formulation and evaluation of Cordia dichotoma fruit mucilage as matrix forming agent for sustained release of propranolol hydrochloride. Int $\mathrm{J}$ Pharm 2015; 5(2): 512-517.

Patil DN, Kulkarni AR, Shahapurkar AA and Patil BS. Release of drug neomycin from Cordia dichotoma transdermal film. International Journal of Pharma and Bio Sciences 2010, 1 (2): 1-5.

Pattnaik S, Swain K, Choudhury P, Acharya PK and Mallick S. Alfuzosin hydrochloride transdermal patches: evaluation of physicochemical, in vitro human cadaver skin permeation and thermodynamic parameters. Int Braz J Urol 2009 ; 35(6):716-29.

Prasad GJ, Sonal RB, Shailesh LP and Priti ST. Plant profile, phytochemistry and pharmacology of Cordia dichotoma (Indian cherry): A review. Asian Pac J Trop Biomed 2013; 3(12): 1009-1012.

Priyanka DA and Shrikant D. A Review on medicinal fruit bhokar of species Cordia dichotoma Forst. International Journal of Pharmaceutical \& Biological Archives 2014; 5(3): 41 - 47.

Radha GV and Santoshnaidu M. Design of transdermal films of alfuzocin $\mathrm{HCl}$ by using a natural polymer tamarind seed polysaccharide extract. Der Pharmacia Lettre 2013; 5 (3):457-464.

Rajesh MG, Paul B and Latha MS. Efficacy of kamilari in alcoholic live cirrhosis, Antiseptic 2000; 97: 320.

Rapisarda A, Ficarra R, Tommasin S, Caldbro ML and Hungsa S. Cordia francisci, C. martinicensis, C. myxa, C. serratifolia and Culmfolia leaves as new source of routine; Analgesic and antiinflammatory activity, Plant Medica 1992; 42:643.
Santoshnaidu M, Radha GV, Girish P and Lohithasu D. Comparison studies on transdermal films of natural tamarind seed polysaccharide extract containing anti hypertension drug with PVA, HPMC and guar gum. World Journal of Pharmaceutical Research 2014; 3 (5): 753-763.

Satyanarayan $\mathrm{P}$, Swaina K, Mallick $\mathrm{S}$ and Zhiqun L. Effect of casting solvent on crystallinity of ondansetron in transdermal films. International Journal of Pharmaceutics 2011; 406: 106110.

Somya G, Nayyar P and Sharma PK. Extraction and characterization of Cordia dichotoma mucilage as pharmaceutical adjuvant. World Journal of Pharmaceutical Research 2015; 4 (2):12991308 .

Sonia D, Abhay A, Ashok KT , Manish J and Gyati S. Development and evaluation of Novel Cordia myxa Fruit gum based mucoadhesive tablets for gastroretentive delivery of losartan Potassium. J Pharm Sci \& Res 2015; 7(9): 652-661.

Rajpur A and Lakshmi PK. Development of reservoir type transdermal drug delivery system of alfuzosin hydrochloride for the treatment of benign prostate hyperplasia. Der Pharmacia Lettre 2015, 7 (4):31-39.

Vidyasagar G, Jadhav AG, Narkhede SP and Narkhede SB. Isolation and Comparative Evaluation of Cordia dichotoma Forst. Mucilage as a binding agent with standard binder. J Chem Pharm Res 2010; 2(4):887-891.

Wassel G, El-Menshaw B, Saud A, Meharuna G and ElMerzabani M. Screening of selected plant for Pyrrolizidine alkaloids and antitumor activity, Pharmazine 1987; 42: 709.

\section{How to cite this article:}

Duppala L, Anepu S, Divvela HND, Teku RL. Assessment of film forming potential of Cordia dichotoma fruit mucilage (Boraginaceae): Alfuzosin hydrochloride as a drug of choice. J App Pharm Sci, 2016; 6 (05): 036-043. 